\title{
The NF2 tumor suppressor gene product, merlin, mediates contact inhibition of growth through interactions with CD44
}

\author{
Helen Morrison, ${ }^{1}$ Larry S. Sherman, ${ }^{2}$ James Legg, ${ }^{3}$ Fatima Banine ${ }^{2}$ Clare Isacke, ${ }^{3}$ Carrie A. Haipek, ${ }^{4}$ \\ David H. Gutmann, ${ }^{4}$ Helmut Ponta, ${ }^{1}$ and Peter Herrlich ${ }^{1,5}$ \\ ${ }^{1}$ Forschungszentrum Karlsruhe, Institute of Toxicology and Genetics, and University of Karlsruhe, Institute of Genetics, \\ 76021 Karlsruhe, Germany; ${ }^{2}$ Department of Cell Biology, Neurobiology \& Anatomy, University of Cincinnati College of \\ Medicine, Cincinnati, Ohio 45267-0521, USA; ${ }^{3}$ Imperial College of Science, Technology and Medicine, London SW7 2AZ, \\ UK, ${ }^{4}$ Department of Neurology, Washington University Medical School, St. Louis, Missouri 63110, USA
}

\begin{abstract}
The neurofibromatosis-2 (NF2) gene encodes merlin, an ezrin-radixin-moesin-(ERM)-related protein that functions as a tumor suppressor. We found that merlin mediates contact inhibition of growth through signals from the extracellular matrix. At high cell density, merlin becomes hypo-phosphorylated and inhibits cell growth in response to hyaluronate (HA), a mucopolysaccharide that surrounds cells. Merlin's growth-inhibitory activity depends on specific interaction with the cytoplasmic tail of CD44, a transmembrane HA receptor. At low cell density, merlin is phosphorylated, growth permissive, and exists in a complex with ezrin, moesin, and CD44. These data indicate that merlin and CD44 form a molecular switch that specifies cell growth arrest or proliferation.
\end{abstract}

[Key Words: NF2; CD44; ezrin; hyaluronate; ERM; Schwann cells]

Received August 8, 2000; revised version accepted February 16, 2001.

In tissues, cells proliferate to occupy the space allotted to them and then stop proliferating when they contact other cells or dense extracellular matrix (Holley 1975). This process, referred to as contact inhibition of growth, first was described decades ago (e.g., Kruse and Miedema 1965; Stoker and Rubin 1967). The mechanisms by which a cell senses when it should stop proliferating still are poorly understood (for review, see Fagotto and Gumbiner 1996), but likely involve specific cell surface receptors that signal cell-cycle arrest and changes in gene expression. Prior to contact inhibition, such sensors would be in a growth permissive state. Here, we describe a candidate sensor complex that exists in both growth inhibitory and growth permissive states that involves the Nf2 tumor suppressor gene product.

Neurofibromatosis type 2 (NF2) is a dominantly inherited autosomal disease affecting 1 in 40,000 individuals (Evans et al. 1992). The hallmark of NF2 is the appearance of bilateral vestibular schwannomas, benign tumors composed of aberrant Schwann cells (Eldridge 1981). The NF2 gene is located on chromosome 22 and

\footnotetext{
${ }^{5}$ Corresponding author.

E-MAIL peter.herrlich@itg.fzk.de; FAX 49-7247-823354.

Article and publication are at www.genesdev.org/cgi/doi/10.1101/ gad.189601.
}

encodes merlin (for moesin-ezrin-radixin-like protein), related to the ezrin-radixin-moesin (ERM) family of band 4.1 proteins (Rouleau et al. 1993; Trofatter et al. 1993). Numerous studies indicate that merlin is a negative growth regulator. In Drosophila chimeras, for example, cells lacking functional merlin hyperproliferate compared to neighboring cells that retain merlin function (LaJeunesse et al. 1998). Mice with conditional homozygous Nf2 mutations targeted to neural crest and Schwann cells develop schwannomas, Schwann-cell hyperplasia, cataracts, and osseous metaplasia (Giovannini et al. 2000), whereas germ line heterozygous $N f 2$ mutant mice develop a variety of aggressive malignancies not typically seen in NF2 patients (McClatchey et al. 1998). Collectively, these data indicate merlin is a tumor and metastasis suppressor.

The N-terminal of merlin is $\sim 65 \%$ homologous to the $\mathrm{N}$-termini of the ERM proteins suggesting that merlin may share some functional properties with ERM proteins. The N-terminal domains of ERM proteins bind in vitro to a motif of charged amino acids in the cytoplasmic portions of the transmembrane proteins CD44, CD43, and ICAM-2 (Legg and Isacke 1998; Yonemura et al. 1998). Merlin could, therefore, compete with ERM proteins for common interaction sites in the cytoplasmic domains of these transmembrane protein partners. Con- 
sistent with this idea, Sainio et al. (1997) found that merlin colocalizes with CD44 and ezrin in cultured cells and that merlin coimmunoprecipitates with CD44. The function of merlin could therefore be linked to extracellular growth signals through its association with transmembrane proteins such as CD44.

The $\mathrm{N}$ - and C-terminal ends of ezrin (Gary and Bretscher 1995), radixin (Magendantz et al. 1995) and merlin (Sherman et al. 1997; Gutmann et al. 1998, 1999; Gonzalez-Agosti et al. 1999; Morrison 2001) can interact physically with one another. In the case of ERM proteins, intramolecular $\mathrm{N}$-terminal binding to the $\mathrm{C}$ terminus is thought to negatively influence interactions with other proteins (Bretscher et al. 1997; Tsukita and Yonemura 1997; Pearson et al. 2000). Intermolecular interactions between $\mathrm{N}$ and $\mathrm{C}$ termini cause oligomer formation between ERM proteins and ERM proteins and merlin (Gary and Brescher 1993; Andréoli et al. 1994; Berryman et al. 1995; Gronholm et al. 1999). In the case of ERM proteins, these intra- and intermolecular interactions appear to be controlled by phosphorylation, indicating that ERM proteins can exist in two functionally different states (Mackay et al. 1997; Matsui et al. 1998; Gautreau et al. 2000). Merlin may be affected similarly by phosphorylation (Shaw et al. 1998).

Using an inducible promoter to drive merlin expression in a rat schwannoma cell line, we have discovered that merlin plays a critical role in the establishment and maintenance of contact inhibition of growth. At high cell density, merlin is activated and blocks proliferation. Its growth-inhibitory function is associated with dephosphorylation and depends on interaction with a specific domain of the cytoplasmic tail of CD44. In logarithmically growing low-density cell cultures, however, CD44 assembles complexes of ERM proteins associated with phosphorylated merlin. The extracellular CD44 ligand HA and antibodies recognizing an extracellular domain of CD44 can induce rapid merlin dephosphorylation and arrest of proliferation in these low-density cultures, thus mimicking contact inhibition of growth as it occurs at high cell density. Our data provide significant clues about how merlin functions as a tumor suppressor and reveal the existence of a novel molecular switch that, under the influence of ligands in the microenvironment, controls the decision of a cell to proliferate or growtharrest.

\section{Results}

Inducible expression of merlin inhibits rat schwannoma cell growth

To study the functions and biochemical activities of merlin, we looked for a cell system in which merlin expression was either lost or aberrantly regulated and that was amenable to biochemical and molecular manipulation. Although several groups have studied human schwannoma cells from NF2 patients in vitro (e.g., Rosenbaum et al. 1998; Pelton et al. 1998; Hung et al. 1999|, these cells cannot be maintained in long-term cul- tures and are difficult to use in biochemical and molecular studies. We therefore chose to examine the possibility of using an ENU-induced rat schwannoma cell line, RT4-D6P2T, which carries an activating mutation of the neu protooncogene (Bargmann and Weinberg 1988). Like other transformed cell types, RT4-D6P2T fails to stop growing at confluency and forms extensive foci.

To determine whether RT4-D6P2T cells were an appropriate cell system for studying merlin function, we examined merlin expression in these cells and compared it to that in normal rat Schwann cells under different culture conditions. In a variety of cell lines, merlin expression is increased significantly in cells that are growth-arrested as a result of confluency or serum deprivation (Shaw et al. 1998). We grew passage-matched primary cultures of normal rat Schwann cells at low and high cell density and assayed for merlin levels by Western blotting. Merlin was expressed at two- to threefold higher levels in confluent Schwann cell cultures compared to low-density cultures, as determined by scanning densitometry (Fig. 1A). In contrast, merlin expression was not increased in RT4-D6P2T cells grown at high cell density in the same culture conditions as the rat Schwann cells (Fig. 1A). These rat schwannoma cells therefore have lost their ability to regulate cell densitydependent merlin expression.

If increased endogenous merlin expression at cell confluency contributed to growth arrest in normal cells, we reasoned that increasing merlin expression in malignant rat schwannoma cells would also inhibit cell growth. We previously had found that stable overexpression of merlin in RT4-D6P2T cells and in another rat schwannoma cell line, JS1, inhibited cell growth both in vitro and in vivo (Sherman et al. 1997). However, the potent growthinhibitory activity of merlin resulted in loss of merlin expression after several cell doublings, making a mechanistic biochemical analysis of merlin's function difficult. Therefore, we generated clones of RT4-D6P2T cells that can be induced to express merlin at various levels (reverse tet; Gossen et al. 1995). Individual clones were selected that, in the noninduced state, expressed merlin at approximately the level of the endogenous gene and in which merlin expression could be induced either sixfold (clone $6_{7}$ ) or 28 -fold (clone $5_{4}$ ) above background following treatment with doxycycline (Fig. 1B). As negative controls, we also generated clones of cells bearing only empty vector and clones that inducibly expressed an NF2 patient-derived inactive merlin mutant, L64P (Fig. 1B).

To determine whether low versus high levels of merlin expression can inhibit malignant rat schwannoma cell growth in vitro, we tested each of the inducible merlin clones in soft agar colony assays. Induction of both low (clone 67) and high (clone $5_{4}$ ) levels of merlin resulted in $40 \%$ to $50 \%$ reductions in colony formation compared to uninduced cells (Fig. 1C). The growth of doxycycline-treated vector control cells and cells induced to express the L64P mutant were unchanged. Thus, increases in merlin expression, proportional to or 10 -fold above the endogenous levels induced in conflu- 

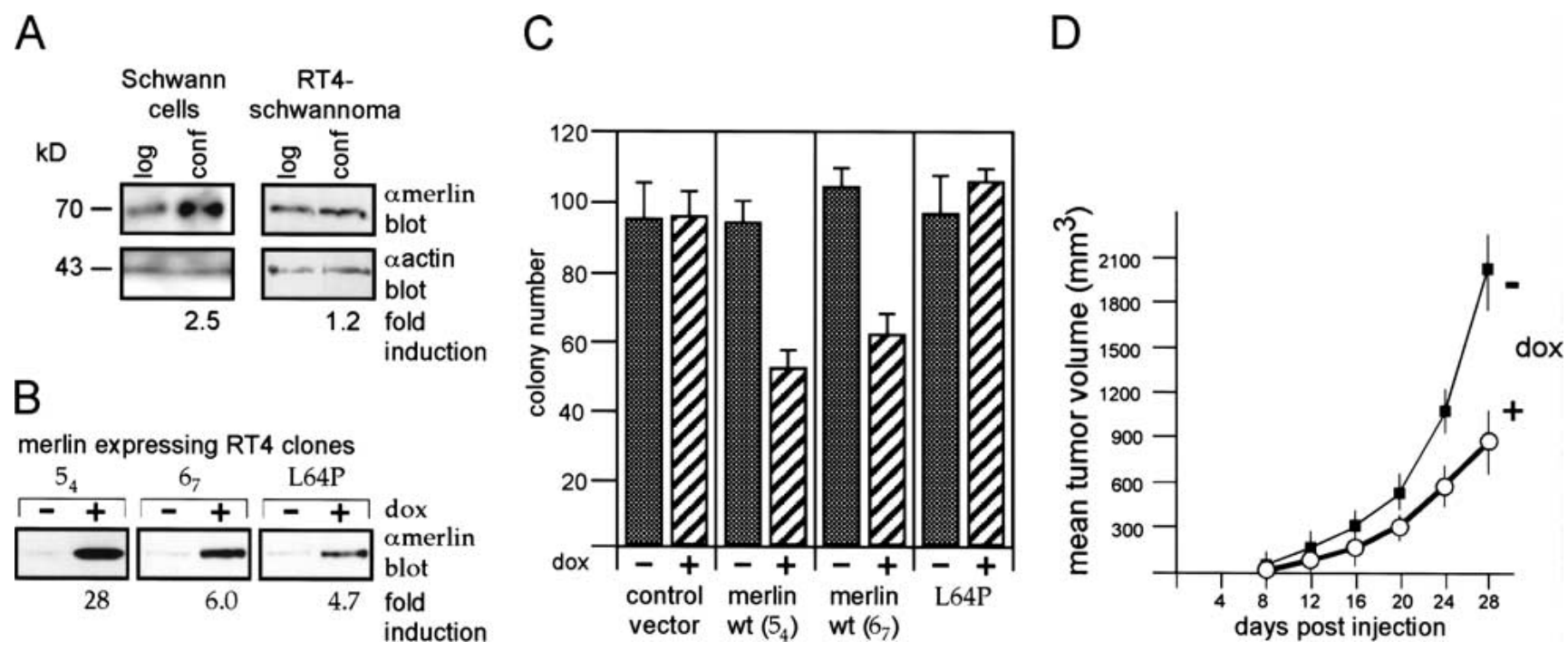

Figure 1. Regulated tumor suppressor function of merlin expressed in the schwannoma cell line RT4-D6P2T. (A) At confluency, merlin expression is increased in primary rat Schwann cells but not in the RT4-D6P2T schwannoma cell line. Primary rat Schwann cells at early passage (2-3) were plated on poly-l-lysine-coated $100 \mathrm{~mm}$ dishes in DMEM + 10\% FCS at high- and low-cell densities, RT4-D6P2T schwannoma cells on uncoated plates. After $24 \mathrm{~h}$, lysates from density-matched cells were produced and resolved on a mini-gel followed by Western blotting using the antimerlin antibody C18 ( $\alpha$ merlin; merlin band at $70 \mathrm{kD}$ ). The equal loading of $25 \mu \mathrm{g}$ of total protein was confirmed by an actin Western blot ( $\alpha$ actin; apparent molecular mass $43 \mathrm{kD}$ ). (B) Doxycycline-inducible merlin expression clones. RT4-D6P2T cells were stably cotransfected with the $\mathrm{r}$-tet regulator and doxycycline-inducible wild-type (clones $5_{4}$ and $6_{7}$ ) and mutant (L64P) merlin constructs. Cells at 70\% confluency were harvested at $8 \mathrm{~h}$ after addition of doxycycline. Resolution of the $70 \mathrm{kD}$ merlin band as in $A$. (C) Merlin reduces agar colony formation. Doxycycline-inducible clones expressing either wild-type merlin (clones $5_{4}$ and 67 ), the mutant L64P, or vector control cells were placed in soft agar (see Material and Methods). Average number of colonies per well were plotted and standard errors indicated. $(D)$ Merlin inhibits tumor growth in vivo. Subcutaneous tumor growth after injection of clone $5_{4}$ cells into nude mice (see Material and Methods). Where indicated, doxycycline was added to the drinking water. The experiments also were performed with clone $6_{7}$ with similar results.

ent normal Schwann cells, inhibit the growth of RT4D6P2T schwannoma cells. To test whether inducible merlin expression could inhibit rat schwannoma cell growth in vivo, $1 \times 10^{5}$ inducible merlin RT4-D6P2T cells (clone $5_{4}$ ) or vector control cells were injected subcutaneously into athymic nude mice. In the absence of doxycycline in the drinking water, both vector control (not shown) and merlin-inducible cells grew to $\sim 200$ $\mathrm{mm}^{3}$ by $14 \mathrm{~d}$ and to $>2000 \mathrm{~mm}^{3}$ within $28 \mathrm{~d}$ (Fig. 1D, -dox). However, in the presence of doxycycline, tumor growth was inhibited consistently by up to $55 \%$ in animals bearing inducible merlin cells (Fig. 1D) but not vector-control cells (not shown). These data verify that merlin inhibits tumor growth in vivo.

\section{Merlin activity is modulated by cell density}

The finding that merlin expression is highest in Schwann cells grown in confluent cultures suggests that the growth-inhibitory activity of merlin may be linked to culture density, a situation mimicked in soft agar and in the animal. To determine whether increased merlin expression also influences the growth of schwannoma cells in culture dishes in a density-dependent manner, inducible merlin cells were plated at low cell density in the presence and absence of doxycycline and assayed for growth over several days. Upon merlin induction, both low- and high-expressing schwannoma clones were growth-inhibited but only at high cell density, which was reached after $3 \mathrm{~d}$ under our experimental conditions (Fig. 2A, clones $5_{4}$ and 67 ). Merlin induction significantly inhibited the formation of foci under these conditions (Fig. 2B). During logarithmic growth, however, neither low- nor high-level induction of merlin expression influenced cell growth. Doxycycline treatment of vector control cells or cells inducibly expressing mutant (L64P) merlin had no effect on cell growth at either density (Fig. 2A).

The lower cell counts observed in confluent schwannoma cultures expressing increased levels of wild-type merlin resulted from growth inhibition and not from apoptosis. No signs of merlin-dependent apoptosis could be detected as assayed by trypan blue permeability, TUNEL assays, and analysis of sub- $G_{1}$ levels of DNA (not shown). In contrast, cells with increased merlin expression had reduced BrdU incorporation $157 \% \pm 8 \%$ less compared to cells with basal expression in clone $6_{7}$; mean from three experiments), an increased number of cells in $\mathrm{G}_{1}(80 \%-83 \%$ in confluent cultures compared to $68 \%-70 \%$ in cultures expressing basal levels of merlin; range over three experiments) and an increase in hypophosphorylated $\mathrm{Rb}$ (Fig. 2A insert, threefold as determined by scanning densitometry). 
Thus, increasing the abundance of merlin in cells is not in itself sufficient to suppress growth. Rather, merlin appears to function in two different states, growth-permissive at low cell density and growth-suppressive at high cell density restoring signaling of contact inhibition of growth in these transformed cells.

\section{Merlin is hypophosphorylated at high cell density}

The finding that merlin has distinct cell density-dependent activities is consistent with the notion that merlin is activated by posttranslational modifications. Shaw et al. (1998) found that merlin is phosphorylated on serine and threonine residues and that merlin dephosphorylation increased with serum deprivation, high cell density, or loss of substratum adhesion. We also detected two merlin bands in Western blots of RT4-D6P2T cell lysates (Fig. 3A,B). A slower migrating band predominated in the nonconfluent cultures whereas a second, faster-migrating band appeared only at confluency. The slower band disappeared upon calf intestinal phosphatase treatment (Fig. $3 \mathrm{~B}$ ), indicating that the faster migrating band was a hypophosphorylated form of merlin. Both the endogenous (Fig. 3A) and doxycycline-induced (Fig. 3B) populations of merlin molecules could be detected in phosphorylated and hypophosphorylated forms. Notice, however, that even when merlin expression was induced to high levels, the hypophosphorylated molecule only was evident in lysates from confluent cultures (Fig. 3B) or from cells grown in soft agar (not shown). Notably, the L64P mutant remained phosphorylated at high cell density, although it could be dephosphorylated with calf intestinal phosphatase (Fig. 3B). These findings suggest that the hypophosphorylated form of merlin is growthinhibitory whereas the phosphorylated form is either inactive or growth-permissive.

Hypophosphorylated merlin, but not ezrin or moesin, binds the cytoplasmic tail of CD44 at high cell density

The observation that merlin phosphorylation and growth-suppressive activity depended on cell density suggests that cell-cell and/or cell-matrix interactions can mediate merlin's function. As the most straightforward assumption, the surface interaction could be transmitted through a receptor to which merlin is associated. ERM proteins and merlin coimmunoprecipitate with CD44 (Tsukita et al. 1994; Sainio et al. 1997), whose ligands include HA and other components of the extracellular matrix. We therefore examined by coimmunoprecipitation whether CD44-merlin association depended on the phosphorylation status of merlin. Only the hypophosphorylated form of endogenous (Fig. 3D) or doxycycline-induced (Fig. 3C) merlin coimmunoprecipitated with CD44 in cultures grown at high cell density, obviously independent of merlin abundance. The L64P merlin mutant protein did not coimmunoprecipitate with CD44 (Fig, 3C). No ezrin or moesin could be detected in these protein complexes although the lysates

\section{A}
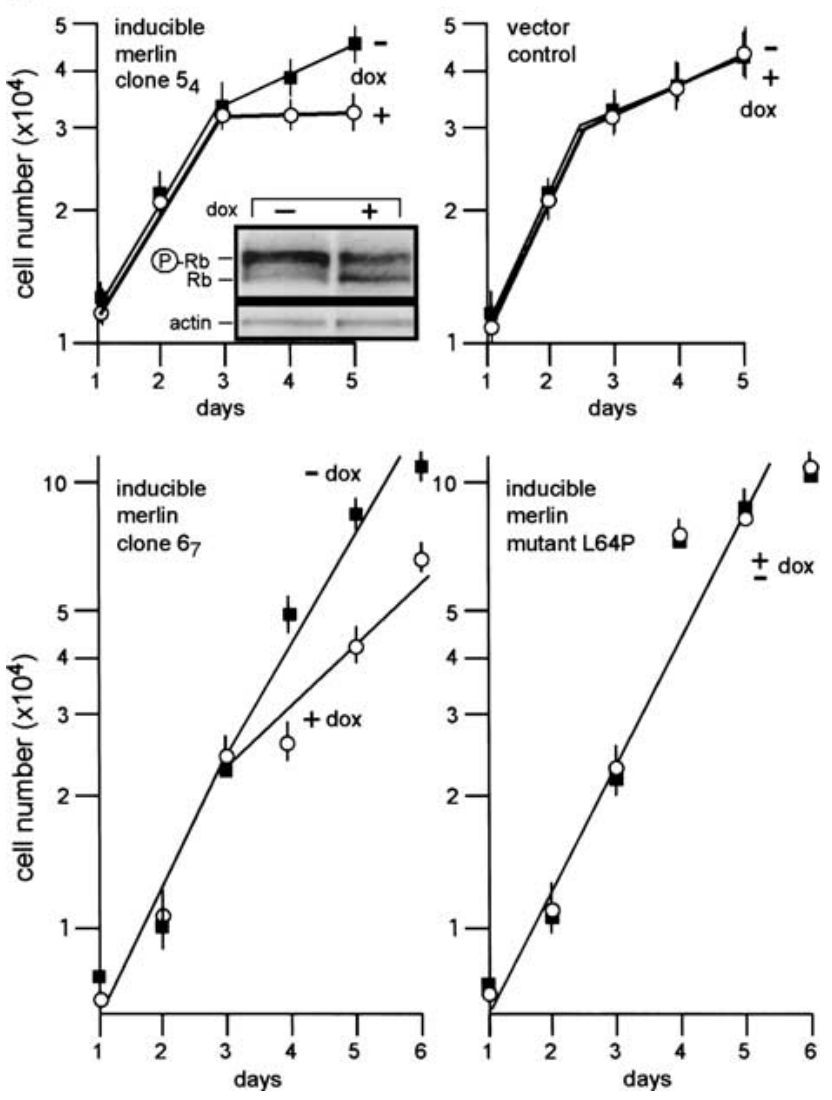

B
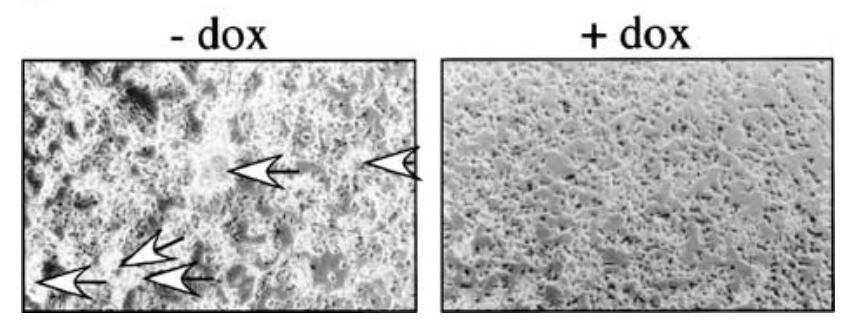

Figure 2. Activation of merlin at high cell density. (A) Wildtype merlin reduces growth in culture dishes but only at high cell density. RT4-D6P2T clones 54,67 , and L64P and vector control cells were seeded at low density (triplicates in 24-well dishes) and cultivated in the presence or absence of doxycycline. Cells per well were counted at 24-h intervals and the numbers plotted starting at $24 \mathrm{~h}$ after seeding. Standard errors are indicated. The insert shows a Western blot using an anti-Rb antibody (and anti-actin loading control) demonstrating that at high cell density (day 3 of culture) in the presence doxycycline, $\mathrm{Rb}$ is hypophosphorylated. Apparent molecular weights of phosphorylated, hypophosphorylated $\mathrm{Rb}$ and of actin are 112, 110, and $43 \mathrm{kD}$, respectively. $(B)$ Merlin reduces foci formation in culture dishes. Photomicrographs of RT4-D6P2T clone 67 cells in culture dishes at day 5 after seeding at low cell density in the absence or presence of doxycycline. Arrows in the left panel indicate large foci. Note absence of focus formation in the right panel.

contained considerable amounts of both proteins (Fig. 3C and D). 
Figure 3. High cell density triggers the activation of merlin and the functionally required association with CD44. A hypophosphorylated form of the endogenous $(A)$ or doxycyclin-induced $(B)$ merlin can be resolved in confluent cultures. Clone $5_{4}$ cells were cultivated without doxycycline (endogenous merlin; $A$ ) or $5_{4}, 6_{7}$, and L64P cells in the presence of doxycycline for $8 \mathrm{~h}(B)$. Equal cell numbers from either logarithmic or confluent (high cell density) growth conditions were lysed and the lysates subjected to a higher resolution gel and Western blotting using the anti-merlin antibody (C18) or anti-actin. Where indicated, merlin was immunoprecipitated prior to gel electrophoresis. "Control IP" defines a precipitation with Sepharose A beads alone. The exposure time in $B$ was about 30 times shorter than in $A$. As indicated, lysates or immunoprecipitates were treated with calf intestinal phosphatase (CIP). The slower migrating band disappears upon digestion with CIP (shown for clone $5_{4}$ ). L64P mutant merlin, however, remained phosphorylated even at cell confluency shown by the fact that the slower migrating band was converted to a faster migrating band upon digestion with CIP. Apparent molecular mass: $70 \mathrm{kD}$ for the phosphorylated merlin form, $69 \mathrm{kD}$ for the hypophosphorylated form. Marker proteins were run with each gel and the sizes confirmed in all experiments. Doxycycline-induced $(C)$ and endogenous $(D)$ hypophosphorylated merlin, but not ezrin and moesin, coprecipitated with CD44 from lysates of high cell density cultures. For coimmunoprecipitation experiments, lysates of high cell density cultures were incubated overnight with the CD44 antibody 5G8 and then treated with protein A sepharose. "Control IP" as in B. Western blotting was performed using either an antimerlin antibody or an anti-ezrin antibody that also recognizes moesin, showing ezrin at a molecular weight of $80 \mathrm{kD}$ and moesin at a molecular weight of $76 \mathrm{kD}$. Mutant merlin L64P is not precipitated with CD44. Sequestering of merlin by binding to overexpressed, soluble CD44 cytoplasmic tails abolishes merlin function $(E)$. The doxycycline-inducible merlin expressing clone $5_{4}$ was stably transfected with expression constructs encoding either a wildtype or mutated CD44 cytoplasmic tail fused to GST or GST alone. The mutant form was chosen for its inability to bind ezrin (see text and Material and Methods). Subclones with high expression levels (see Western blot with an anti-CD44 tail-specific antibody $[\alpha \mathrm{CD} 44$ tail]) were selected, placed in soft agar, and their colony forming ability (see Material and Methods) was determined in the presence or absence of doxycycline. By pull-down experiments $(F)$ the association of merlin with the wild type, but not the mutant cytoplasmic tail of CD44, was confirmed. To this end, cells of clone 67 transfected with either wild-type or mutant CD44 tail constructs, were plated at high cell density. Eight hours after doxycycline addition, the cells were lysed and the CD44 tails enriched by GSH agarose and protein resolved by mini-gel. Western blotting was performed using either anti-merlin (C-18), anti-ezrin, or anti-CD44 tail antibodies. Note that the resolution of the gels differs from those in $A$ through $D$.

To explore whether merlin required association with CD44 for its function, we generated stable clones of our inducible cell lines that overexpressed the cytoplasmic tail of CD44 fused to GST as a soluble cytoplasmic peptide. We predicted that the soluble CD44 tail would sequester merlin from its site of activation and interfere with merlin activity. The expression levels of the cytoplasmic fusion protein were 20-fold higher than those of endogenous CD44 (Fig. 3E; compare the intensity of the $34 \mathrm{kD}$ band indicating transfected CD44 tails with that of the $85 \mathrm{kD}$ band reflecting full-length endogenous CD44). The CD44 tail-GST fusion protein indeed 
blocked growth inhibition by merlin in soft agar whereas expression of GST alone had no effect (Fig. 3E).

Ezrin binds in vitro to two clusters of basic amino acids in a membrane-proximal nine amino-acid motif of the CD44 cytoplasmic tail (Legg and Isacke 1998). To determine whether merlin interacted with CD44 through the same domain as ERM proteins, we generated a CD44 tail-GST fusion protein with mutations in the ERM protein-binding domain and stably expressed it in our inducible merlin cell lines. Overexpression of this mutant protein could not abrogate merlin-mediated growth inhibition in soft agar (Fig. 3E). Furthermore, in pull-down experiments, merlin bound to wild type but not mutant CD44 tails, verifying the specificity of this effect (Fig. 3F). Neither ezrin nor moesin were bound to the CD44 cytoplasmic tails under these high cell density conditions.

These data indicate that the attachment of hypophosphorylated merlin to the membrane-anchored CD44 tail, or to other transmembrane proteins with an ERM-binding amino acid motif, is an essential determinant of merlin's function as a negative growth regulator at high cell density conditions.

At low cell density, ezrin, moesin, and the phosphorylated form of merlin are associated with CD44

The finding that hypophosphorylated merlin, but not ERM proteins, bound CD44 through the ERM binding motif in high cell density cultures suggested that ERM proteins and merlin may associate with CD44 under different cellular conditions. We therefore repeated the CD44 coprecipitation experiments in low-density cultures. In contrast to high-density cultures, ezrin and moesin were coimmunoprecipitated with CD44 in logarithmically growing cultures (Fig. 4A,B). Interestingly, merlin also was found in the complex, but in its phosphorylated form. This result was confirmed in precipitation experiments using the CD44 cytoplasmic tail-GST fusion proteins (Fig. 4C). This CD44-merlin association is likely to be indirect through ERM proteins because phosphorylated merlin was immunoprecipitated with an antiezrin/moesin antibody (labeled oezrin, although it recognizes both proteins) from lysates of low-density cultures, whereas at high cell density, no such association could be detected (Fig. 4D).

\section{CD44 ligands influence merlin activity}

CD44 appears to be at least one transmembrane partner for merlin that mediates the activity of merlin in response to growth conditions. To test if a ligand that binds CD44 can influence the effects of merlin on cell growth, we grew our inducible merlin cell clones in the presence of a soluble CD44 protein containing the nonvariant extracellular portion of the protein /CD44 occurs in several splice variants, the extracellular portion of the

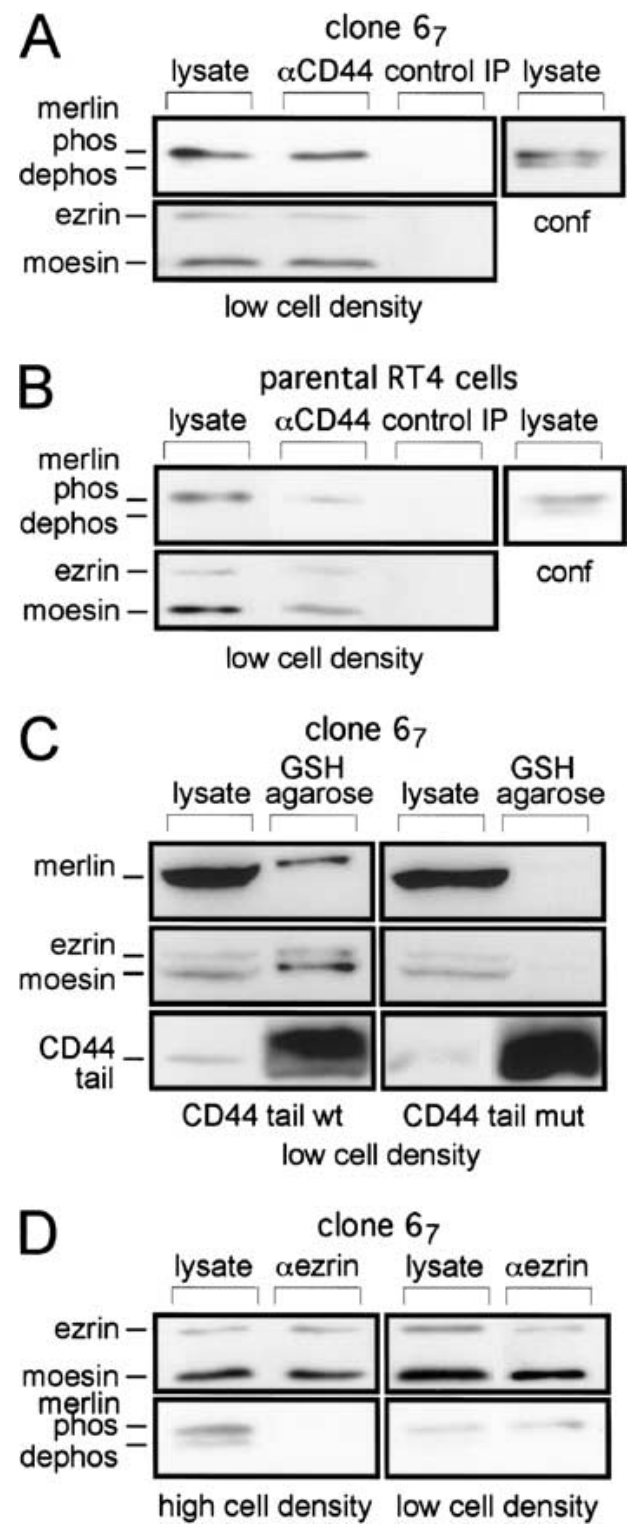

Figure 4. Ezrin, moesin, and phosphorylated merlin are complexed with CD44 at low cell density. Ezrin, moesin, and doxycycline-induced $(A)$ or endogenous $(B)$ phosphorylated merlin are coprecipitated with CD44. For coimmunoprecipitation experiments, clone $6_{7}$ cells and parental RT4-D6P2T were seeded at low cell density. All procedures were as in Fig. 3C and D. Lysates of clone $6_{7}$ cells at high cell density (conf) were included to control for the resolution of merlin modifications. Overexpressed wild-type cytoplasmic tail of CD44 pulls down merlin, ezrin, and moesin from lysates of cells at low cell density $(C)$. Cells of clone $6_{7}$ transfected with either wild-type or mutant CD44 tail constructs, were plated at low cell density. Eight hours after doxycycline addition, the cells were lysed and the CD44 tails enriched by GSH agarose. Procedures as in Fig. 3F. Phosphorylated merlin coprecipitates with ezrin and moesin at low cell density $(D)$. Clone $6_{7}$ cells were plated at low or high density and treated with doxycycline for $8 \mathrm{~h}$. Coimmunoprecipitation was performed as described in $A$, except for the use of an antiezrin/moesin antibody (C-19) for the precipitation. Lysates were subjected to a higher resolution gel. Western blotting as in $A$. 
smallest CD44 protein was used here) to sequester ligands away from the endogenous CD44 proteins. Treatment with soluble CD44 abolished the growth-inhibitory effect of increased merlin expression (Fig. 5A, right side, confluent conditions). In contrast, a soluble CD44 protein with mutations in the glycosaminoglycan-binding domain failed to reverse merlin-mediated growth inhibition (Fig. 5A, right side, confluent conditions) suggesting that a glycosaminoglycan ligand of CD44 could be responsible for promoting the growth-inhibitory activity of merlin in confluent cells.

We previously found that RT4-D6P2T cells and other malignant rat schwannoma cell lines synthesize the glycosaminoglycan HA, and that CD44 was a major HA receptor in these cells (Sherman et al. 1995). We therefore tested if treating logarithmically growing cultures with HA (which binds CD44 through the glycosaminoglycan binding domain) would result in merlin dephosphorylation and growth inhibition as observed in confluent cultures. Cells with increased merlin expression treated with HA were growth-inhibited (Fig. 5B) and demonstrated increased levels of hypophosphorylated merlin within $5 \mathrm{~min}$ of HA addition (insert to Fig. 5B).
HA had no effect on schwannoma cells with basal levels of merlin expression or cells induced to express the L64P mutant form of merlin (not shown). These data suggest that CD44 is the major mediator of merlin activity in these cells.

Interestingly, we found that in contrast to confluent growth conditions, both soluble CD44 and CD44 that is mutant in the glycosaminoglycan binding domain inhibited the growth of logarithmically growing schwannoma cells expressing increased levels of merlin (5A left side, logarithmic growth). Within $5 \mathrm{~min}$ of adding soluble CD44, we observed an $\sim$ fourfold increase (as determined by scanning densitometry) in the hypophosphorylated form of merlin in these cultures (Fig. 5A insert). Although the mechanism by which the soluble proteins inhibit growth under these conditions is unclear, our data suggest that unidentified ligands are sequestered from endogenous CD44 by both the wild-type and mutant-soluble CD44 proteins.

These data indicate that at least two specific and different ligands are bound to CD44, one specifying logarithmic growth and another (hyaluronate) mediating contact inhibition in confluent cells.
Figure 5. CD44 ligands influence merlin activity. The soluble extracellular domain of CD44 sequesters different ligands from either logarithmically growing or confluent cells. Cells of clone $5_{4}$ were seeded in triplicates into 24-well plates and treated with doxycycline to induce merlin expression. Either on day 1 (logarithmically growing cells) or on day 3 (confluent cells) $10 \mathrm{ng} / \mathrm{mL}$ of the soluble extracellular domain of CD44, produced in COS-7 cells as described (Bartolazzi et al. 1994), was added, either as wild-type form (solCD44wt) or as mutant-peptide defective in glycosaminoglycan binding (solCD44mut). As control, cells without doxycycline were treated identically (not shown). Both solCD44wt or solCD44mut activated merlin in logarithmically growing cells (left growth curve, seen as reduced growth rate), whereas merlin activity was blocked in confluent cultures (right growth curve, seen as reversal of growth inhibition by merlin), and this effect was dependent on the presence of the glycosaminoglycan-binding motif. Similar results were obtained with clone $6_{7}$. The insert shows a Western blot (higher-resolution gel) detecting doxycycline-induced merlin ( $\alpha$-merlin C-18) from lysates of clone $5_{4}$ cells at low cell density prior $(0 \mathrm{~min})$ or after treatment with $10 \mathrm{ng} / \mathrm{mL}$ of solCD44wt for $5 \mathrm{~min}$. HA-dependent growth inhibition in logarithmically growing schwannoma cells overexpressing merlin. Cells of clone $6_{7}$ were seeded in triplicates into 24-well plates. Doxycycline and HA $(100 \mu \mathrm{g} / \mathrm{mL})$ were added as indicated $1 \mathrm{~d}$ prior to the cell counts shown. HA addition to doxycyclineinduced cells caused retardation of growth (left panel). Doxycycline alone did not affect growth during logarithmic phase (see also Fig. 2A). Similar results were obtained with clone $5_{4}$. The insert shows a Western blot (higher resolution gel) detecting doxycycline-induced merlin from lysates of clone $6_{7}$ cells at low density prior (0 min) or after treatment with $100 \mu \mathrm{g} / \mathrm{mL}$ of HA for $5 \mathrm{~min}$.
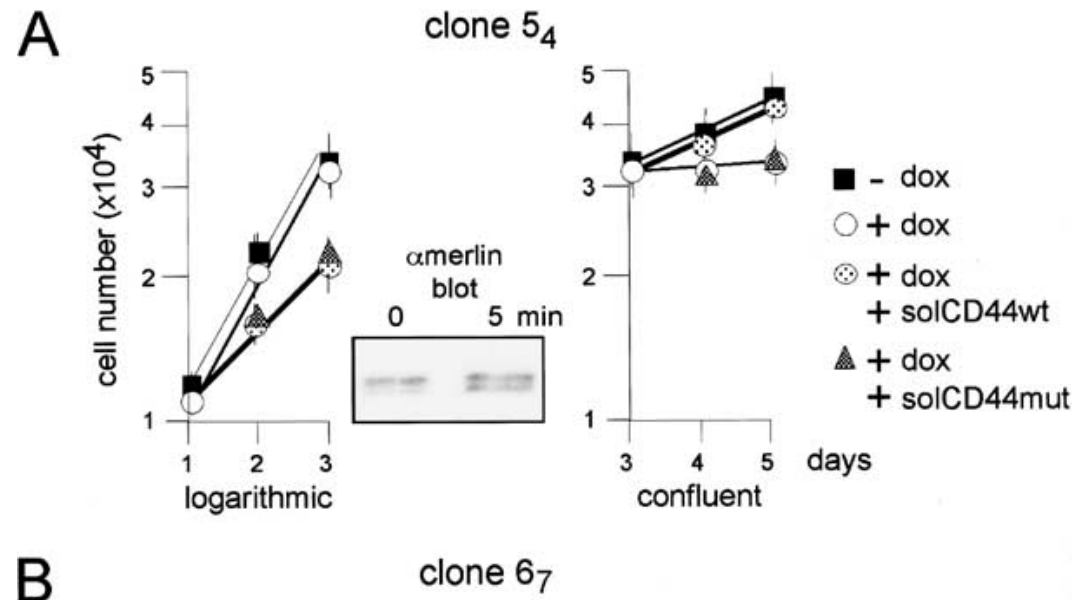

B

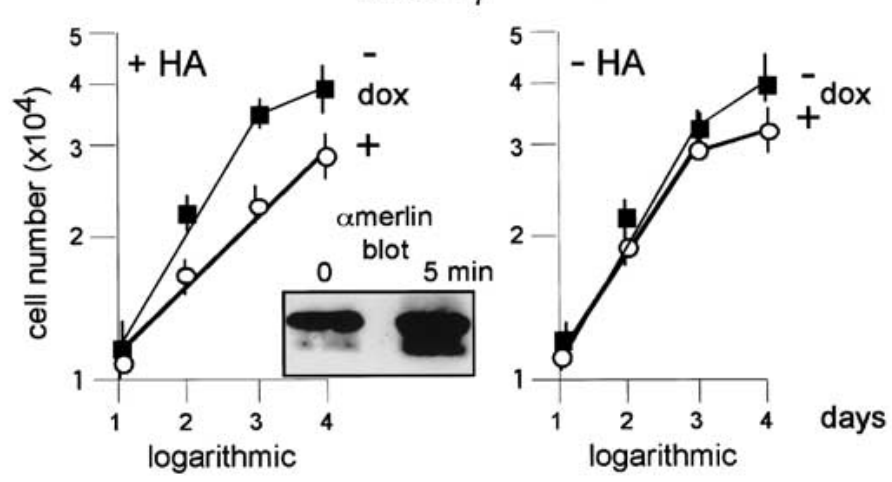


CD44 mediates merlin-dependent growth inhibition in several cell lines

To ascertain if CD44 is the major mediator of merlin activity in the rat schwannoma clones and if the CD44merlin protein complex also functions in other cell types, we tested if specific anti-CD44 antibodies could mimic the effects of HA, and if HA-dependent growth inhibition could be reproduced in several cell lines. In logarithmically growing RT4-D6P2T-inducible merlin cell clones, both HA and a CD44-specific antibody, IM7, induced hypophosphorylation of merlin and inhibited cell growth (Figs. 5B and 6A). HA treatment of murine NIH3T3, canine MDCK, and rat kangaroo Ptk2 cells, also caused merlin dephosphorylation and inhibited cell proliferation (Fig. 6B,C). These data directly link CD44 to HA-induced growth inhibition through merlin, and indicate that the CD44-merlin protein complex functions in cell types other than the RT4-D6P2T cell line.

As a second test of the requirement for CD44 in mediating HA-induced activation of merlin's growth inhibitory function, we transfected both wild-type rat CD44s and CD44s with point mutations in the ERM-binding domain into a human melanoma cell line (RP-MC) that lacks endogenous CD44 (Thomas et al. 1992), but which expresses endogenous merlin (not shown). HA had no effect on BrdU incorporation of logarithmically growing RP-MC cells transfected with empty vector (Fig. 6B). However, HA significantly inhibited BrdU incorporation in RP-MC cells expressing wild-type CD44 but not the mutant defective in merlin and ERM binding (Fig. 6B). These data confirm that CD44 absolutely is required for HA-mediated activation of the growth suppressive function of merlin.

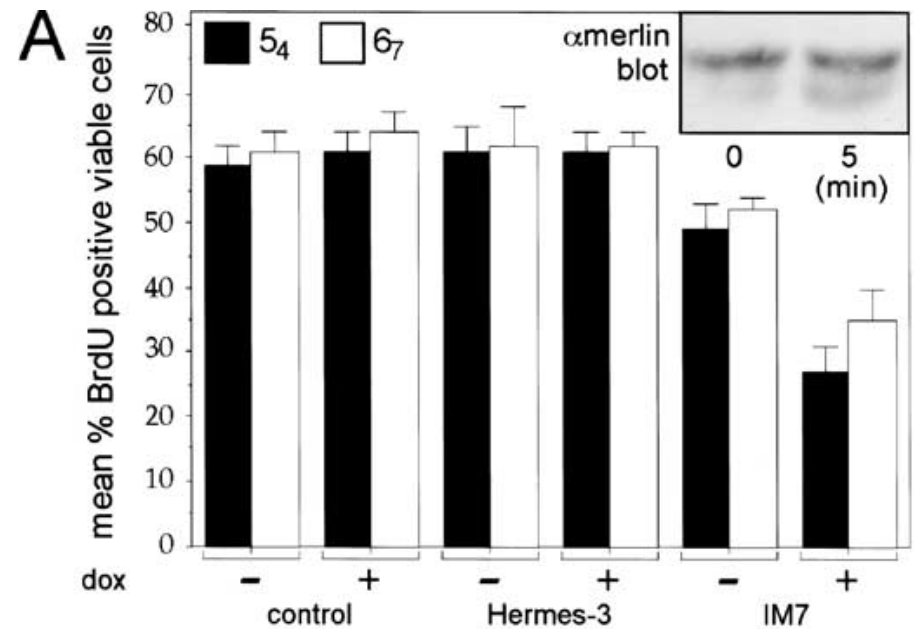

B
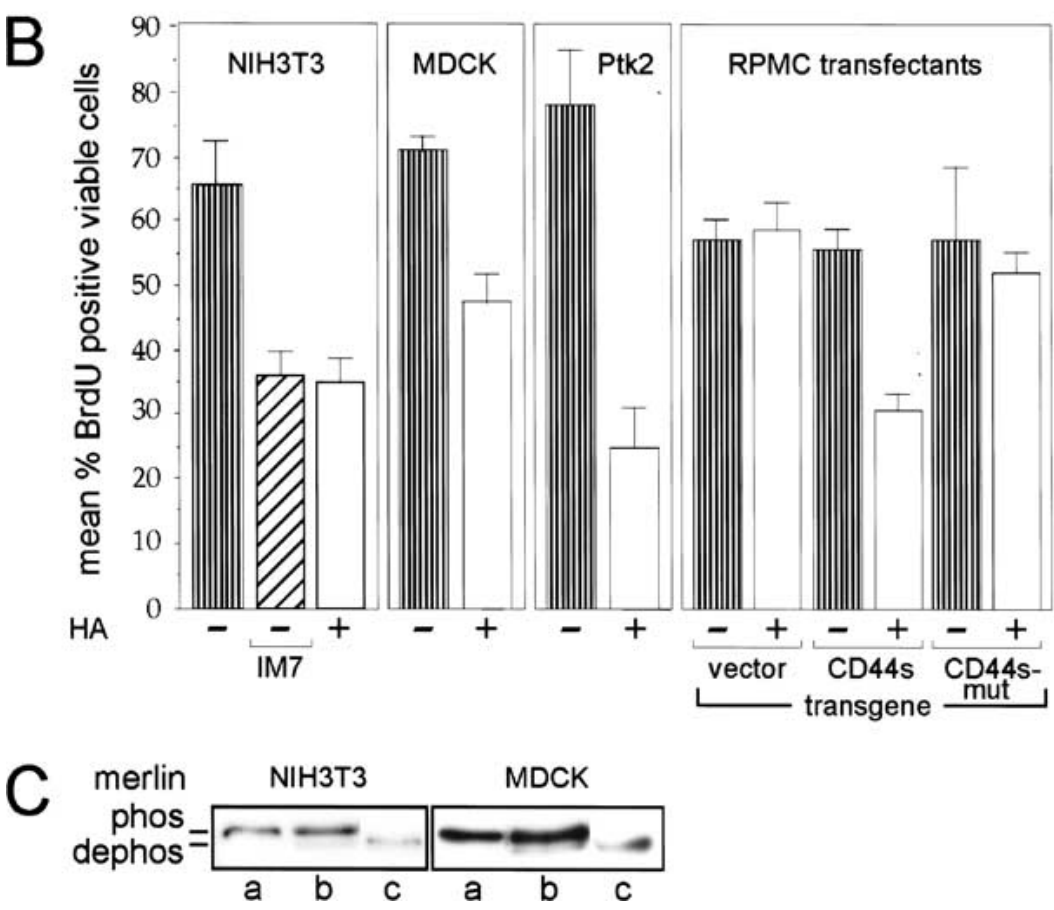

Figure 6. CD44-dependent merlin activation and growth inhibition in several cell lines. $(A)$ The CD44-specific antibody IM7 activates merlin. Cells from clones $5_{4}$ and $6_{7}$ were seeded into 8-well chamber slides at low density. Either IM7 or Hermes-3 (control antibody) and doxycycline were added where indicated and incubated for 12 h (control cells were without antibody). Cells then were labeled with BrdU for $60 \mathrm{~min}$ and stained for incorporation using a biotinylated BrdU antibody. The mean percent cells that incorporated BrdU, are plotted and standard errors are indicated. The insert shows a Western blot (higher resolution gel) detecting doxycycline-induced merlin ( $\alpha$-merlin C-18) from lysates of clone $6_{7}$ cells at low density prior $(0 \mathrm{~min})$ or after treatment with IM7 for $5 \mathrm{~min}$. (B) CD44-dependent activation of merlin and inhibition of growth in several types of cells. All cells were seeded into 8-well chamber slides at low density and incubated with HA or IM7 where indicated, for $12 \mathrm{~h}$. BrdU incorporation and detection as in A. The CD44 antibody IM7 (as well as KM81, not shown) inhibited proliferation of NIH3T3 cells similarly to the result in $A$. HA activated merlin in mouse fibroblasts (NIH3T3 cells), in dog kidney epithelial cells (MDCK), and rat kangaroo epithelial cells (Ptk2). In addition cells negative for CD44 when stably transfected with a construct encoding full-length CD44s but not CD44 mutated in the ERM-binding domain, were also growth-inhibited in response to HA treatment. $(C)$ Addition of HA induces dephosphorylation of merlin in several types of cells. NIH3T3 and MDCK cells as in $B$ were harvested untreated (a) or after treatment with $100 \mu \mathrm{g} / \mathrm{mL}$ of HA (b) for $12 \mathrm{~h}$ (similar dephosphorylation after $5 \mathrm{~min}$, not shown). Cell lysates were treated with CIP $(\mathrm{c})$ prior to Western blotting (higher-resolution gel) as in $A$. 
Morrison et al.

\section{Discussion}

We provide evidence that three band 4.1 family members, merlin, ezrin, and moesin, are involved in a molecular switch that signals cellular growth or growth inhibition. Merlin expression is increased in normal rat Schwann cells at high cell density but is not regulated by cell density in a malignant rat schwannoma cell line. Increasing merlin expression in these transformed cells to a degree similar to that observed in confluent normal Schwann cells is sufficient to inhibit growth, but only at high cell density. Under these conditions, merlin is dephosphorylated and interacts with CD44. Ezrin and moesin are not detected in this complex. The association with CD44 is necessary for merlin action on cell proliferation. In logarithmically growing cells, however, merlin has no influence on cell growth, is phosphorylated, and is in a complex with ezrin and moesin. This complex also is associated with the cytoplasmic tail of CD44. The CD44 ligand, HA, as well as antibodies that mimic CD44 ligands can imitate the effects of high cell density in logarithmically growing cells, rapidly inducing merlin dephosphorylation and inhibiting cell growth.

A molecular switch that instructs a cell when intercellular or cell-matrix contact has occurred should exist in two conformations: a cell proliferation-inhibiting mode and a growth-permissive mode. We propose that merlin and CD44 together function as one such molecular switch and that the growth-inhibiting state of this switch is induced by HA binding to CD44, resulting in merlin hypophosphorylation and direct association with the ERM-binding domain of the CD44 cytoplasmic tail (Fig. 7). We predict that this switch is at least partly controlled by one or several phosphatases that are associated directly with the complex. In contrast, the growth-permissive protein complex consists of CD44 in association with ezrin, moesin, and phosphorylated merlin (Fig. 7). It is conceivable that protein kinases that maintain CD44-ERM association and prevent merlin activation also would be associated with this complex. Although not addressed here, the function of ezrin also will likely depend on association with CD44 or a similar

\section{growth promoting mode}

\section{growth inhibitory mode}
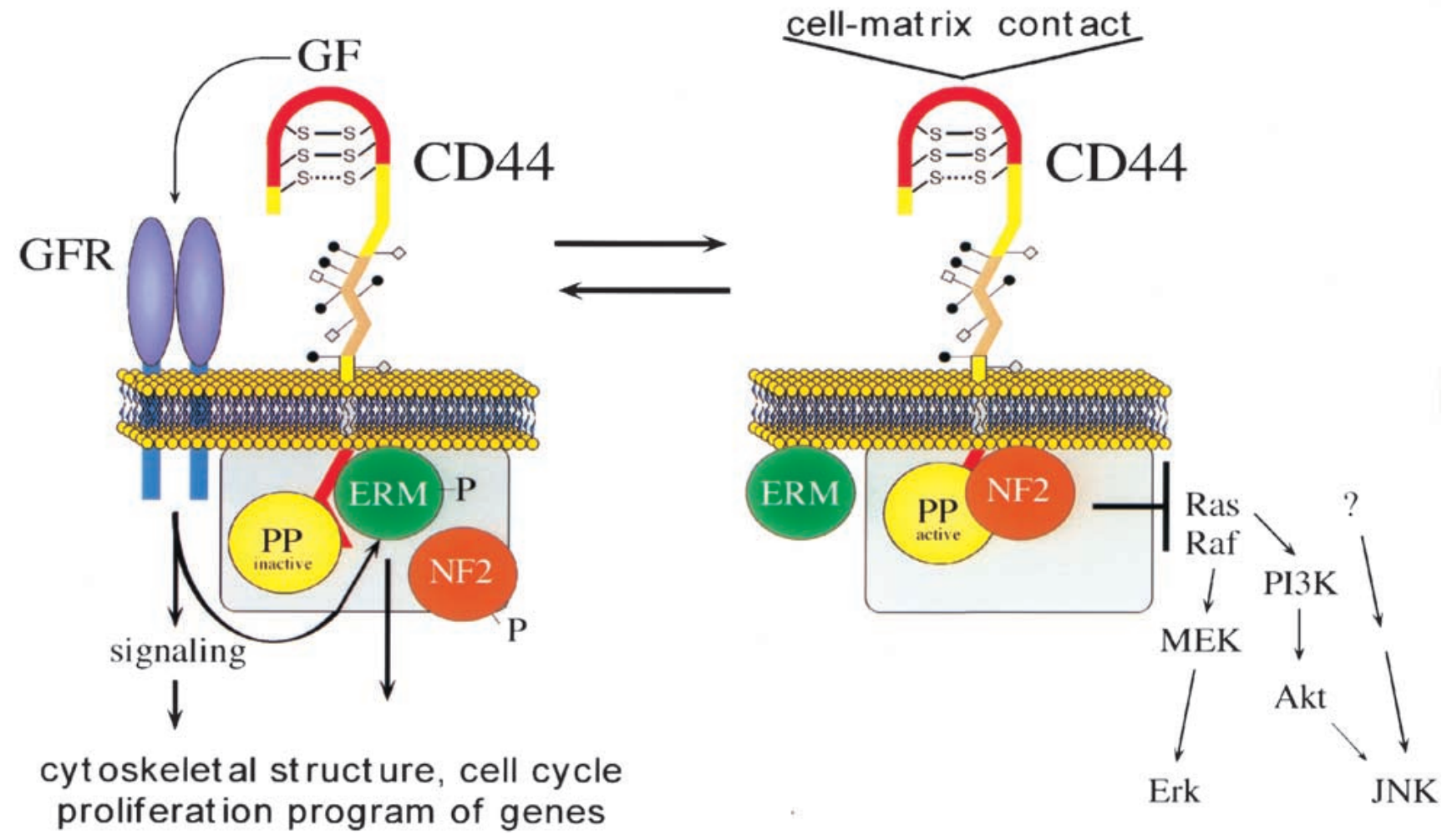

Figure 7. Model of CD44 action in logarithmic and confluent growth conditions. Specific ligands determine two functional states of CD44 that influence cytoplasmic complexes. The ligands of the growth mode have not been defined. It is, however, known that CD44, and particularly the larger-splice variants, serve as platform for the activation of growth factors (GF; Bourguignon et al. 1997; Sherman et al. 1998; Van der Voort et al. 1999; Sherman et al. 2000; V. Orian-Rousseau, L. Chen, P. Herrlich, and H. Ponta, unpubl.). (GFR) growth-factor receptor; (PP) protein phosphatase. Additional components are likely associated with the CD44-bound complexes (gray boxes). 
transmembrane protein. When we kept the CD44 tail overexpressors in low-density culture for several days (in contrast to cells in confluence), we invariably lost tail expression (not shown) suggesting that sequestering ezrin away from CD44 was not compatible with proliferation.

The coprecipitation experiments do not reveal how the components of the protein complexes at the cytoplasmic tail of CD44 are linked to one another. Because mutant merlin L64P, which is not dephosphorylated, is never found associated with CD44, we favor the interpretation that phosphorylated merlin cannot bind to CD44 directly. It is associated, however, with ezrin/ moesin as shown by the coprecipitations using ezrin/ moesin-specific antibodies. This interpretation is consistent with a number of previous in vitro studies showing merlin-ERM heterodimers (Huang et al. 1998; Gronholm et al. 1999).

The ability of merlin to function as a negative growth regulator may depend on the inhibition of several signal transduction pathways. Indeed, we found that activated merlin interfered with JNK activation and PDGF-dependent activation of Erk and PI3K (H. Morrison, H. Ponta, and P. Herrlich, unpubl.). Using dominantly active mutants of Ras, Raf, and MEK allowed us to localize the step of interference to a level above MEK (H. Morrison, H. Ponta, and P. Herrlich, unpubl.).

HA is likely to be one ligand that signals cells to stop growth as shown by the sequestering data with soluble extracellular CD44 proteins and by HA-induced growth inhibition in a variety of logarithmically growing cells. Furthermore, hyaluronidase could reverse cell densitydependent merlin activation (H. Morrison, H. Ponta, and P. Herrlich, unpubl.). HA is a key component of many extracellular matrices, surrounds cells as they grow, and will, upon confluent cell growth, reach concentrations high enough to activate merlin. The idea that HA could trigger contact inhibition of growth is consistent with its numerous roles in tissue formation (Laurent et al. 1996; Camenisch et al. 2000).

Treating logarithmically growing cells with soluble CD44 proteins surprisingly resulted in merlin hypophosphorylation and growth inhibition, suggesting that growth-promoting (or permissive) ligands (different from HA) associate with CD44 in low cell density conditions. Data from our group and others indicate that CD44 can sequester growth factors, including many that promote cell proliferation (Bennett et al. 1995; Jackson et al. 1995; Sherman et al. 1998, 2000; V. Orian-Rousseau, L. Chen, P. Herrlich, and H. Ponta, unpubl.). Such growth-promoting factors presumably would prevent merlin dephosphorylation and growth-inhibitory activity. Consistent with this idea, Shaw et al. (1998) found that merlin is dephosphorylated rapidly when cells are treated with trypsin, which likely abolishes ligand binding.

Consistent with findings in several other types of cells (Shaw et al. 1998), we found that total merlin protein levels increase in primary rat Schwann cells at confluency. In the malignant rat schwannoma cells, however, merlin levels are not up-regulated with increasing cell density, an effect probably related to transformation by the dominant oncogene neu. The fact that increasing merlin expression in these transformed cells blocked cell growth at high cell density suggests that merlin levels must reach a certain plateau in transformed cells before it can exert its negative growth activity.

The ERM proteins have been implicated in actin polymerization mediating the formation of lamellipodia, microvilli, and cell-matrix adhesion sites (for review, see Tsukita and Yonemura 1997). Therefore, it is possible that part of merlin's growth-altering function depends on interactions with the actin cytoskeleton. In a series of preliminary experiments, we found that stress fiber formation following cell replating was altered severely in our doxycycline-treated RT4-D6P2T cells (not shown). These findings are consistent with previous observations where merlin overexpression in rat cells /Gutmann et al. 1999) or lack of expression in human schwannoma cells (Pelton et al. 1998; Rosenbaum et al. 1998) resulted in altered cytoskeletal organization. Interestingly, a highdensity-dependent block of c-Jun activation by various stimuli of NIH3T3 cells depended on the integrity of the actin cytoskeleton (Lallemand et al. 1998), suggesting a link between cytoskeletal organization and signal transduction.

In addition to the CD44-merlin complex described in this report, other mechanisms are known to mediate cell contact-dependent inhibition of growth. Contact inhibition can be triggered by the addition of cell membrane preparations to dividing cells in vitro (e.g., Whittenberger and Glaser 1977; Peterson and Lerch 1983). A glycoprotein from such membranes could mimic the effect of cell-cell contact (Wieser et al. 1990). Adhesion molecules, including particular cadherins and integrins, induce cell cycle arrest upon contact with specific components of the extracellular matrix or with neighboring cells (Aoki et al. 1991; Takahashi and Suzuki 1996; Giancotti and Ruoslahti 1999). Presumably, these mechanisms operate in concert or in hierarchy to mediate cellular responses to contact with extracellular matrix and with other cells.

In conclusion, we find that merlin and CD44 interact to mediate at least one set of signals that are critical for matrix and cell density dependent growth inhibition. This growth regulatory circuit would be disrupted in schwannomas and other tumors with NF2 mutations, such that cells could not transduce signals mediated by proliferation-inhibitory CD44 ligands. Our observations have significant implications for understanding how loss of merlin contributes to tumorigenesis and tumor progression and for developing ways to target aberrantly active parts of this growth regulatory pathway.

\section{Materials and methods}

Growth factors and reagents

Doxycycline (Sigma, Deisenhofen); HA (Healon; high molecular weight; Pharmacia \& Upjohn, Erlangen); glutathione agarose (Santa Cruz, CA); Nonidet P-40 (NP40; Boehringer Mannheim). 


\section{Antibodies}

C-18 rabbit polyclonal antibodies from Santa Cruz were used to detect merlin. Antibodies against the cytoplasmic tail of CD44 were produced according to standard methods and will be described elsewhere. Sources of other antibodies: to the retinoblastoma protein (C-15), ezrin (C-19) and actin (I-19) from Santa Cruz; to CD44 (IM7, Pharmingen, San Diego; KM81, ATCC; Hermes-3, gift of Sirpa Jalkanen, Turku; 5G8 as described in Sleeman et al. 1996).

\section{Plasmid constructs}

pUHD17-1 encoding the reverse tetracycline-dependent transactivator (rtTA), pUHC13-3 rtTA-responsive luciferase reporter, and pUHD10-3 rtTA-responsive cloning vector (Gossen and Bujard 1992; Gossen et al. 1995) were kindly provided by Hermann Bujard (Heidelberg). EcoR1 fragments encoding either the complete merlin cDNA (NF2.17) or merlin mutant cDNA (NF2.L64P, Gutmann et al. 1999) were subcloned into pUHD10-3.

CMV promoter-driven expression constructs encoding the truncated extracellular domain of CD44 (Aruffo et al. 1990), a mutant of the HA binding motif (Bartolazzi et al. 1994), and the cytoplasmic tail of CD44 inserted into pEBG-3x (Legg and Isacke 1998) were prepared as described as was the mutant CD44 tail construct defective in ezrin binding (alanine substitutions for arginines at positions 293 and 294 and for lysines at positions 298, 299, and 300). The plasmids used for transfection of RP-MC cells express CD44s or CD44s mutated in the ezrin binding domain (see above) in the pcDNA3 vector (Invitrogen, DeShelp).

\section{Cell cultures}

The RT4-D6-P2T schwannoma cell line, NIH3T3 mouse fibroblasts, and COS-7 cells were purchased from the European Collection of Animal Cell Cultures (Salisbury). RP-MC cells were kindly provided by Dr. I. Stamenkovic (MGH, Boston). MDCK cells and Ptk2 cells were kindly provided by Dr. J. Wehland (GBF Braunschweig). RT4-D6-P2T, NIH3T3, COS-7, and RPMC cells were grown in Dulbecco's modified Eagle's medium (DMEM; GIBCO-BRL, Karlsruhe) supplemented with 10\% fetal bovine serum (GIBCO-BRL). MDCK and Ptk2 cells in RPMI 1640 were supplemented with glutamine and $10 \%$ fetal bovine serum. All cells were maintained in a humidified atmosphere with $5 \% \mathrm{CO}_{2}$ at $37^{\circ} \mathrm{C}$. Primary rat Schwann cells were prepared and grown as described (Kim et al. 1997).

\section{Stable and transient transfection of cells}

All transfections were done in 6-well plates using the liposomal transfection reagent DOTAP (Boehringer Mannheim). To generate stable clones, cells were cotransfected using the plasmids (Invitrogen) pCEP4 (for hygromycin), pBabe (for puromycin), and pcDNA3.1 (for G418), and grown with appropriate antibiotic selection.

\section{Generation of doxycycline-inducible merlin cell lines}

The rtTA expression construct pUHD17-1 was cotransfected together with the puromycin-marker into the RT4-D6-P2T rat schwannoma cell line. Thirty independent puromycin-resistant clones (at $1 \mu \mathrm{g} / \mathrm{mL}$ ) were analyzed for their ability to induce expression of the tet-responsive luciferase reporter construct pUHC13-3 in a transient transfection assay (Gossen et al. 1995). Three founder clones with low spontaneous expression but high inducibility of luciferase expression upon treatment with doxycycline were obtained. In these founder cell lines, doxycyclineinducible wild-type and mutant merlin expression was established by stable cotransfection of the appropriate plasmids (encoding NF2.17, NF2.L64P) with a neomycin marker. Independent G418-resistant clones (at $500 \mu \mathrm{g} / \mathrm{mL}$ ) were selected. The dose of doxycycline in all in vitro experiments was $1 \mu \mathrm{g} / \mathrm{mL}$

\section{Tumor growth in vivo}

Schwannoma RT4-D6-P2T cells $\left(5 \times 10^{5}\right)$ equipped with the doxocycline-inducible merlin construct, suspended in calcium/ magnesium-free PBS, were injected subcutaneously into the right flank of nude mice. Tumor volumes were determined by caliper measurements. Each data point represents the mean tumor volume of four animals \pm standard error. Doxycycline (100 $\mu \mathrm{g} / \mathrm{mL}$ ) was added to the drinking water 1 wk prior to tumor implantation and throughout the experiment.

\section{Cellular growth in vitro}

For BrdU incorporation assays, cells were plated (see below) into 8 -well chamber slides (Lab-Tek), BrdU incorporated for $60 \mathrm{~min}$, and stained for BrdU as recommended by the manufacturer (Oncogene Research Products).

Soft agar colony assay Cells were trypsinized and resuspended in complete medium. 1/10 volume of heated $3.3 \%$ soft agar was added and $1.25 \times 10^{3}$ cells were seeded into each well of a 24well plate. After solidification at $4^{\circ} \mathrm{C}$ for $2 \mathrm{~min}$, the plates were incubated and the colonies counted after $7 \mathrm{~d}$.

Growth in culture dishes For the determination of growth curves, cells were seeded at low density into each well of a 24-well plate and triplicates were counted every $24 \mathrm{~h}$.

Definition of growth condition Low cell density /= logarithmic growth condition) is defined as $24 \mathrm{~h}$ after seeding 500 cells/ $\mathrm{cm}^{2}$. High cell density (= confluent growth condition) is defined as $24 \mathrm{~h}$ after seeding $5 \times 10^{3}$ cells $/ \mathrm{cm}^{2}$.

\section{Immunoprecipitation}

To immunoprecipitate merlin, $2-4 \times 10^{6}$ cells were washed once in ice-cold PBS before lysing the cells on ice with $1 \mathrm{~mL}$ of lysis buffer per plate $(50 \mathrm{mM}$ Tris at $\mathrm{pH} 7.4,150 \mathrm{mM} \mathrm{NaCl}, 3$ $\mathrm{mM} \mathrm{MgCl} 2,0.5 \%$ NP-40, $1 \mathrm{mM}$ PMSF, $10 \mu \mathrm{g} / \mathrm{mL}$ Aprotinin, 10 $\mu \mathrm{g} / \mathrm{mL}$ Leupeptin). DNA was sheared through a 26-gauge needle and the lysate was cleared. The supernatant was incubated with $5 \mu \mathrm{g} / \mathrm{mL}$ merlin antibody (A-19) slowly rotating overnight at $4^{\circ} \mathrm{C}$. Thirty microliters of protein A agarose (Dianova) was added and the mixture rotated at $4{ }^{\circ} \mathrm{C}$ for another $3 \mathrm{~h}$. Immune complexes were washed $4 \times$ with cold lysis buffer and dissolved in $50 \mu \mathrm{L}$ of $2 \times$ Laemmli sample buffer. For calf intestinal phosphatase (CIP) treatment, the lysate was incubated with 1 unit of $\mathrm{CIP}$ at $37^{\circ} \mathrm{C}$ for $1 \mathrm{~h}$ prior to immune precipitation. Coimmunoprecipitations were done as described above, except that a different lysis buffer was used $(20 \mathrm{mM}$ Tris at $\mathrm{pH} 7.4,50 \mathrm{mM}$ $\mathrm{NaCl}, 3 \mathrm{mM} \mathrm{MgCl}, 0.5 \% \mathrm{NP} 40$ ) and the supernatant was incubated with $5 \mu \mathrm{g} / \mathrm{mL}$ of either a CD44 antibody (5G8) or an ezrin antibody (C-19). For pull-downs, lysates of CD44 cytoplasmic tail expressing cells were treated with $30 \mu \mathrm{L}$ glutathione agarose. The precipitates were resolved either on a higher resolution gel (8\% SDS-PAGE, 30-cm length) or on a lower-resolution mini-gel (10\% SDS-PAGE, $5 \mathrm{~cm})$. 


\section{Immunoblotting}

After gel electrophoresis proteins were transferred to Immobilon membranes (Millipore, Eschborn) that were treated with blocking buffer (10\% skimmed milk, $0.1 \%$ Tween, $10 \mathrm{mM}$ Tris at $\mathrm{pH} 7.6,100 \mathrm{mM} \mathrm{NaCl}$ ) at room temperature for $1 \mathrm{~h}$, followed by incubation with primary antibodies in blocking buffer for another hour at room temperature. After three washes, the membranes were incubated with secondary antibody at room temperature for $1 \mathrm{~h}$ and developed and visualized using enhanced chemiluminescence (Amersham, Braunschweig).

\section{Acknowledgments}

We thank Nancy Ratner for helpful comments and for providing normal rat Schwann cells and Jürgen Wehland for advice. This work was supported by DFG (He551/8-2), Fonds der Chemischen Industrie, the Arthritis Research Campaign (to J.L.), NIH NS 39550 (to L.S.) and NIH NS 35848 (to D.G.).

The publication costs of this article were defrayed in part by payment of page charges. This article must therefore be hereby marked "advertisement" in accordance with 18 USC section 1734 solely to indicate this fact.

\section{References}

Andreoli, C., Martin, M., Le Borgne, R., Reggio, H., and Mangeat, P. 1994. Ezrin has properties to self-associate at the plasma membrane. J. Cell Sci. 107: 2509-2521.

Aoki, J., Umeda, M., Takio, K., Titani, K., Utsumi, H., Sasaki, M., and Inoue, K. 1991. Neural cell adhesion molecule mediates contact-dependent inhibition of growth of near-diploid mouse fibroblast cell line m5S/1M. T. Cell Biol. 115: 1751-1761.

Aruffo, A., Stamenkovic, I., Melnick, M., Underhill, C.B., and Seed, B. 1990. CD44 is the principal cell surface receptor for hyaluronate. Cell 61: 1303-1313.

Bargmann, C.I. and Weinberg, R.A. 1988. Increased tyrosine kinase activity associated with the protein encoded by the activated neu oncogene. Proc. Natl. Acad. Sci. 85: 5394-5398.

Bartolazzi, A., Peach, R., Aruffo, A., and Stamenkovic, I. 1994 Interaction between CD44 and hyaluronate is directly implicated in the regulation of tumor development. I. Exp. Med. 180: 53-66.

Bennett, K.L., Jackson, D.G., Simon, J.C., Tanczos, E., Peach, R., Modrell, B., Stamencovic, I., Plowman, G., and Aruffo, A. 1995. CD44 isoforms containing exon v3 are responsible for the presentation of heparin-binding growth factor. J. Cell Biol. 128: 687-698.

Berryman, M., Gary, R., and Bretscher, A. 1995. Ezrin oligomers are major cytoskeletal components of placental microvilli: A proposal for their involvement in cortical morphogenesis. J. Cell Biol. 131: 1231-1242.

Bourguignon, L.Y., Zhu, H., Chu, A., Iida, N., Zhang, L., and Hung, M.C. 1997. Interaction between the adhesion receptor, CD44, and the oncogene product, p185HER2, promotes human ovarian tumor cell activation. I. Biol. Chem. 272: 27913-27918.

Bretscher, A., Reczek, D., and Berryman, M. 1997. Ezrin: A protein requiring conformational activation to link microfilaments to the plasma membrane in the assembly of cell surface structures. J. Cell Sci. 110: 3011-3018.

Camenisch, T.D., Spicer, A.P., Brehm-Gibson, T., Biesterfeldt, J., Augustine, M.L., Calabro, Jr., A., Kubalak, S., Klewer, S.E., and McDonald, J.A. 2000. Disruption of hyaluronan syn- thase- 2 abrogates normal cardiac morphogenesis and hyaluronan-mediated transformation of epithelium to mesenchyme. J. Clin. Invest. 106: 349-360.

Eldridge, R. 1981. Central neurofibromatosis with bilateral acoustic neuroma. Adv. Neurol. 29: 57-65.

Evans, D.G., Hudson, S.M., Donnai, D., Neary, W., Blair, V., Teare, D., Newton, V., Strachan, T., Ramsden, R., and Harris, R. 1992. A genetic study of type 2 neurofibromatosis in the United Kingdom. I. Prevalence, mutation rate, fitness, and confirmation of maternal transmission effect on severity. J. Med. Genet. 29: 841-846.

Fagotto, F. and Gumbiner, B.M. 1996. Cell contact-dependent signaling. Dev. Biol. 180: 445-454.

Gary, R. and Bretscher, A. 1993. Heterotypic and homotypic associations between ezrin and moesin, two putative membrane-cytoskeletal linking proteins. Proc. Natl. Acad. Sci. 90: $10846-10850$.

Gary, R. and Bretscher, A. 1995. Ezrin self-association involves binding of an N-terminal domain to a normally masked Cterminal domain that includes the F-actin binding site. Mol. Biol. Cell 6: 1061-1075.

Gautreau, A., Louvard, D., and Arpin, M. 2000. Morphogenic effects of ezrin require a phosphorylation-induced transition from oligomers to monomers at the plasma membrane. $J$. Cell Biol. 150: 193-203.

Giancotti, F.G. and Ruoslahti, E. 1999. Integrin signaling. Science 285: 1028-1032.

Giovannini, M., Robanus-Maandag, E., van der Valk, M., NiwaKawakita, M., Abramowski, V., Goutebroze, L., Woodruff, M., Berns, A., and Thomas, G. 2000. Conditional biallelic $\mathrm{Nf2}$ mutation in the mouse promotes manifestations of human neurofibromatosis type 2. Genes \& Dev. 14: 1617-1630.

Gonzalez-Agosti, C., Wiederhold, T., Herndon, M.E., Gusella, J., and Ramesh, V. 1999. Interdomain interaction of merlin isoforms and its influence on intermolecular binding to NHE-RF. I. Biol. Chem. 274: 34438-34442.

Gossen, M. and Bujard, H. 1992. Tight control of gene expression in mammalian cells by tetracycline- responsive promoters. Proc. Nat1. Acad. Sci. 89: 5547-5551.

Gossen, M., Freundlieb, S., Bender, G., Muller, G., Hillen, W., and Bujard, H. 1995. Transcriptional activation by tetracyclines in mammalian cells. Science 268: 1766-1769.

Gronholm, M., Sainio, M., Zhao, F., Heiska, L., Vaheri, A., and Carpen, O. 1999. Homotypic and heterotypic interaction of the neurofibromatosis 2 tumor suppressor protein merlin and the ERM protein ezrin. J. Cell Sci. 112: 895-904.

Gutmann, D.H., Geist, R.T., Xu, H., Kim, J.S., and SaporitoIrwin, S. 1998. Defects in neurofibromatosis 2 protein function can arise at multiple levels. Hum. Mol. Genet. 7: 335345.

Gutmann, D.H., Sherman, L., Seftor, L, Haipek, C., Hoang Lu, K., and Hendrix, M. 1999. Increased expression of the NF2 tumor suppressor gene product, merlin, impairs cell motility, adhesion and spreading. Hum. Mol. Genet. 8: 267-275.

Holley, R.W. 1975. Control of growth of mammalian cells in cell culture. Nature 258: 487-490.

Huang, L., Ichimaru, E., Pestonjamasp, K., Cui, X., Nakamura, H., Lo, G.Y., Lin, F.I., Luna, E.J., and Furthmayr, H. 1998. Merlin differs from moesin in binding to F-actin and in its intra- and intermolecular interactions. Biochem. Biophys. Res. Commun. 248: 548-553.

Hung, G., Faudoa, R., Li, X., Xeu, Z., Brackmann, D.E., Hitselberg, W., Saleh, E., Lee, F., Gutmann, D.H., Slattery III, W., Rhim, J.S., and Lim, D. 1999. Establishment of primary vestibular schwannoma cultures from neurofibromatosis type-2 patients. Int. J. Oncol. 14: 409-415. 
Kim, H.A., Ling, B., and Ratner, N. 1997. Nf1-deficient mouse Schwann cells are angiogenic and invasive and can be induced to hyperproliferate: Reversion of some phenotypes by an inhibitor of farnesyl protein transferase. Mol. Cell. Biol. 17: 862-872.

Kruse, Jr., P.F. and Miedema, E. 1965. Production and characterization of multiple-layered populations of animal cells. J. Cell Biol. 27: 273-279.

LaJeunesse, D.R., McCartney, B.M., and Fehon, R.G. 1998. Structural analysis of Drosophila merlin reveals functional domains important for growth control and subcellular localization. J. Cell Biol. 141: 1589-1599.

Lallemand, D., Ham, J., Garbay, S., Bakiri, L., Traincard, F., Jeannequin, O., Pfarr, C.M., and Yaniv, M. 1998. Stress-activated protein kinases are negatively regulated by cell density. EMBO J. 17: 5615-5626.

Laurent, T.C., Laurent, U.B., and Fraser, J.R. 1996. The structure and function of hyaluronan: An overview. Immunol. Cell Biol. 74: A1-A7.

Legg, J.W. and Isacke, C.M. 1998. Identification and functional analysis of the ezrin-binding site in the hyaluronan receptor, CD44. Curr. Biol. 8: 705-708.

Mackay, D.J., Esch, F., Furthmayr, H. and Hall, A. 1997. Rhoand rac-dependent assembly of focal adhesion complexes and actin filaments in permeabilized fibroblasts: An essential role for ezrin/radixin/moesin proteins. I. Cell Biol. 138: 927-938.

Magendantz, M., Henry, M.D., Lander, A., and Solomon, F. 1995. Interdomain interactions of radixin in vitro. J. Biol. Chem. 270: 25324-25327.

Matsui, T., Maeda, M., Doi, Y., Yonemura, S., Amano, M., Kaibuchi, K., and Tsukita, S. 1998. Rho-kinase phosphorylates $\mathrm{COOH}$-terminal threonines of ezrin/radixin/moesin (ERM) proteins and regulates their head-to-tail association. J. Cell Biol. 140: 647-657.

McClatchey, A.I., Saotome, I., Mercer, K., Crowley, D., Gusella, J.F., Bronson, R.T., and Jacks, T. 1998. Mice heterozygous for a mutation at the Nf2 tumor suppressor locus develop a range of highly metastatic tumors. Genes \& Dev. 12: 11211133.

Pearson, M.A., Reczek, D., Bretscher, A., and Karplus, P.A. 2000. Structure of the ERM protein moesin reveals the FERM domain fold masked by an extended actin binding tail domain. Cell 101: 259-270.

Pelton, P.D., Sherman, L.S., Rizvi, T.A., Marchionni, M.A., Wood, P., Friedman, R.A., and Ratner, N. 1998. Ruffling membrane, stress fiber, cell spreading and proliferation abnormalities in human Schwannoma cells. Oncogene 17: 2195-2209.

Peterson, S.W. and Lerch, V. 1983. Inhibition of DNA synthesis in SV3T3 cultures by isolated 3T3 plasma membranes. $J$. Cell Biol. 97: 276-279.

Rosenbaum, C., Kluwe, L., Mautner, V.F., Friedrich, R.E., Muller, H.W., and Hanemann, C.O. 1998. Isolation and characterization of Schwann cells from neurofibromatosis type 2 patients. Neurobiol. Dis. 5: 55-64.

Rouleau, G.A., Merel, P., Lutchman, M., Sanson, M., Zucman, J., Marineau, C., Hoang-Xuan, K., Demczuk, S., Desmaze, C., Plougastel, B., et al. 1993. Alteration in a new gene encoding a putative membrane-organizing protein causes neuro-fibromatosis type 2. Nature 363: 515-521.

Sainio, M., Zhao, F., Heiska, L., Turunen, O., den Bakker, M., Zwarthoff, E., Lutchman, M., Rouleau, G.A., Jaaskelainen, J., Vaheri, A., et al. 1997. Neurofibromatosis 2 tumor suppressor protein colocalizes with ezrin and CD44 and associates with actin-containing cytoskeleton. J. Cell Sci.
110: $2249-2260$

Shaw, R.J., McClatchey, A.I., and Jacks, T. 1998. Regulation of the neurofibromatosis type 2 tumor suppressor protein, merlin, by adhesion and growth arrest stimuli. J. Biol. Chem. 273: 7757-7764.

Sherman, L., Skroch-Angel, P., Moll, J., Schwecheimer, K., Ponta, H., Herrlich, P., and Hofmann, M. 1995. Schwann cell tumors express characteristic patterns of CD44 splice variants. J. Neurooncol. 26: 171-184.

Sherman, L., Wainwright, D., Ponta, H., and Herrlich, P. 1998. A splice variant of CD44 expressed in the apical ectodermal ridge presents fibroblast growth factors to limb mesenchyme and is required for limb outgrowth. Genes \& Dev. 12: 10581071.

Sherman, L., Xu, H.M., Geist, R.T., Saporito-Irwin, S., Howells, N., Ponta, H., Herrlich, P., and Gutmann, D.H. 1997. Interdomain binding mediates tumor growth suppression by the NF2 gene product. Oncogene 15: 2505-2509.

Sherman, L.S., Rizvi, T.A., Karyala, S., and Ratner, N. 2000. CD44 enhances neuregulin signaling by Schwann cells. J. Cell Biol. 150: 1071-1084.

Sleeman, J.P., Arming, S., Moll, J.F., Hekele, A., Rudy, W., Sherman, L.S., Kreil, G., Ponta, H., and Herrlich, P. 1996. Hyaluronate-independent metastatic behavior of CD44 variantexpressing pancreatic carcinoma cells. Cancer Res. 56: 3134-3141.

Stoker, M.G. and Rubin, H. 1967. Density dependent inhibition of cell growth in culture. Nature 215: 171-172.

Takahashi, K. and Suzuki, K. 1996. Density-dependent inhibition of growth involves prevention of EGF receptor activation by E-cadherin-mediated cell-cell adhesion. Exp. Cell Res. 226: 214-222.

Thomas, L., Byers, H.R., Vink, J., and Stamenkovic, I. 1992. $\mathrm{CD} 44 \mathrm{H}$ regulates tumor cell migration on hyaluronatecoated substrate. J. Cell Biol. 118: 971-977.

Trofatter, J.A., MacCollin, M.M., Rutter, J.L., Murrell, J.R., Duyao, M.P., Parry, D.M., Eldridge, R., Kley, N., Menon, A.G., Pulaski, K., et al. 1993. A novel moesin-, ezrin-, radixin-like gene is a candidate for the neurofibromatosis 2 tumor suppressor. Cell 72: 791-800.

Tsukita, S., Oishi, K., Sato, N., Sagara, J., Kawai, A., and Tsukita, S. 1994. ERM family members as molecular linkers between the cell surface glycoprotein CD44 and actin-based cytoskeletons. J. Cell Biol. 126: 391-401.

Tsukita, S. and Yonemura, S. 1997. ERM proteins: Head-to-tail regulation of actin-plasma membrane interaction. Trends Biochem. Sci. 22: 53-58.

van der Voort, R., Taher, T.E., Wielenga, V.J., Spaargaren, M., Prevo, R., Smit, L., David, G., Hartmann, G., Gherardi, E., and Pals, S.T. 1999. Heparansulfate-modified CD44 promotes hepatocyte growth factor/scatter factor-induced signal transduction through the receptor tyrosine kinase c-Met. J. Biol. Chem. 274: 6499-6506.

Whittenberger, B. and Glaser, L. 1977. Inhibition of DNA synthesis in cultures of $3 \mathrm{~T} 3$ cells by isolated surface membranes. Proc. Natl. Acad. Sci. 74: 2251-2255.

Wieser, R.J., Schutz, S., Tschank, G., Thomas, H., Dienes, H.P., and Oesch, F. 1990. Isolation and characterization of a 60$70-\mathrm{kD}$ plasma membrane glycoprotein involved in the contact-dependent inhibition of growth. J. Cell Biol. 111: 26812692.

Yonemura, S., Hirao, M., Doi, Y., Takahashi, N., Kondo, T., and Tsukita, S. 1998. Ezrin/radixin/moesin (ERM) proteins bind to a positively charged amino acid cluster in the juxta-membrane cytoplasmic domain of CD44, CD43, and ICAM-2. J. Cell Biol. 140: 885-895. 


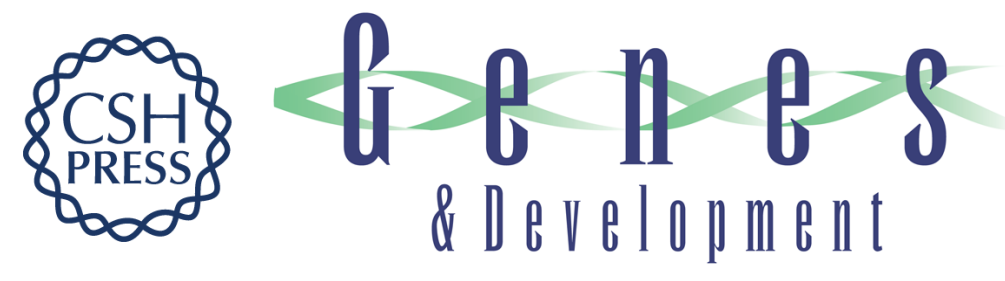

\section{The NF2 tumor suppressor gene product, merlin, mediates contact inhibition of growth through interactions with CD44}

Helen Morrison, Larry S. Sherman, James Legg, et al.

Genes Dev. 2001, 15:

Access the most recent version at doi:10.1101/gad.189601

$\begin{array}{ll}\text { References } & \begin{array}{l}\text { This article cites } 59 \text { articles, } 38 \text { of which can be accessed free at: } \\ \text { http://genesdev.cshlp.org/content/15/8/968.full.html\#ref-list-1 }\end{array}\end{array}$

License

Email Alerting

Receive free email alerts when new articles cite this article - sign up in the box at the top Service right corner of the article or click here.

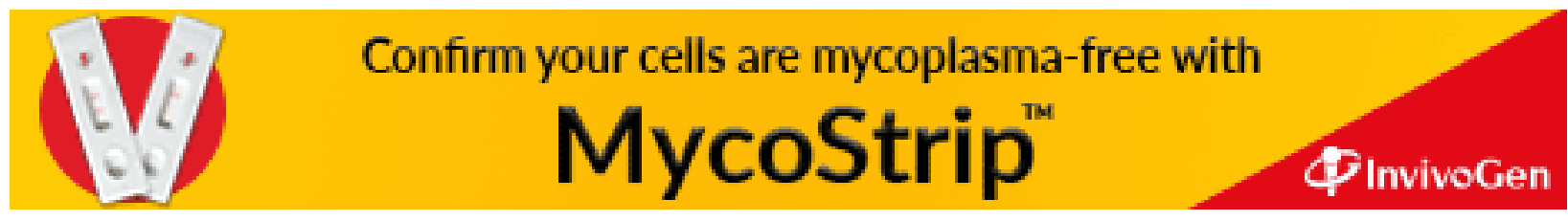

